\title{
Workplace Violence in Emergency Departments in Turkey
}

\author{
Mustafa Sabak ${ }^{1} \quad$ Ameer Al-Hadidi $\quad$ Mehmet Murat Oktay ${ }^{3} \quad$ Behcet Al $^{1} \quad$ Tanyeli Kazaz $^{1}$ \\ Terry Kowalenko ${ }^{4}$ Wael Hakmeh ${ }^{1}$
}

${ }^{1}$ Department of Emergency Medicine, University of Gaziantep School of Medicine, Gaziantep, Turkey

${ }^{2}$ Department of Surgery, Beaumont Health, Royal Oak, Michigan, United States

${ }^{3}$ Department of Emergency Medicine, Hasan Kalyoncu University, Gaziantep, Turkey

${ }^{4}$ Department of Emergency Medicine, Medical University of South Carolina, Charleston, South Carolina, United States

\begin{abstract}
Address for correspondence Wael Hakmeh, DO, Department of Emergency Medicine, University of Gaziantep School of Medicine, Gaziantep, Turkey (e-mail: whakmeh@yahoo.com).
\end{abstract}

\begin{abstract}
Keywords

- workplace

- violence

- emergency

- turkey

- attack

- injury

Background Studies on workplace violence against physicians in emergency departments (EDs) in Turkey are lacking.

Methods To describe the frequency and types of workplace violence, a 34-question online survey of the past 12 months was sent to physicians working in EDs in Turkey. Types of violence were categorized as verbal threats, physical assaults, confrontation, stalking, and sexual harassment.

Results A total of 366 physicians completed the survey; 4 were excluded (minimum 20 hours/week). Sixty-two percent of respondents were men. Ninety-nine percent reported verbal abuse and 54\% reported physical violence. Family members, not patients, were the most common perpetrators of every form of workplace violence. Hospitals limiting the number of visitors and loitering had $14 \%$ reduction in physical threats. Only $23 \%$ of respondents indicated that their hospital offered information about preventing and managing workplace violence even though $86 \%$ noted interest. Only $1 \%$ never had fear, even though $89 \%$ indicated they had security staff. Over $89 \%$ felt that hospital security was lacking in number and ability to protect. For $82 \%$, workplace violence affected their ability to provide patient care. Ninety percent indicated that current laws do not adequately protect them. There was also no statistically significant difference in any type of workplace violence based on the timing or length of shifts, type of hospital, or number of hours worked. Of all types of violence reported, only stalking demonstrated a statistically significant difference between men and women.

Conclusion Workplace violence is a real danger for physicians working in EDs in Turkey, similar to other countries, demonstrating that this problem transcends borders. Further studies should assess root causes of violent behaviors of patients and their visitors, as well as possible (administrative, social, and legal) mechanisms to minimize such violence. Hospitals that limited the number of visitors and empowered security officers were associated with decreased violence.
\end{abstract}

DOI https://doi.org/ $10.1055 / \mathrm{s}-0041-1732284$ ISSN 2231-0770
C 2021. Syrian American Medical Society.

This is an open access article published by Thieme under the terms of the Creative Commons Attribution-NonDerivative-NonCommercial-License, permitting copying and reproduction so long as the original work is given appropriate credit. Contents may not be used for commercial purposes, or adapted, remixed, transformed or built upon. (https://creativecommons.org/licenses/by-nc-nd/4.0/).

Thieme Medical and Scientific Publishers Pvt. Ltd. A-12, 2nd Floor, Sector 2, Noida-201301 UP, India 


\section{Introduction}

Workplace violence is a serious health hazard that affects many occupations. More serious violent injuries occur in health care from workplace violence than in all other industries combined. ${ }^{1}$

Health care providers suffering from workplace violence are more likely to experience posttraumatic stress disorder, feelings of insecurity, and worse rates of job satisfaction. ${ }^{2}$ Employers of victims also suffer economically as they are the ones to primarily shoulder the financial burden for medical and psychological treatments rendered. ${ }^{3}$ Prior studies have reported high and increasing levels of workplace violence in emergency departments (EDs) across the globe, ${ }^{4}$ with targets including nurses, ${ }^{5,6}$ attending physicians, and emergency medicine residents. ${ }^{7-12}$ Studies on workplace violence affecting physicians working in EDs throughout Turkey are lacking.

This study surveyed physicians working in EDs in Turkey about incidents of workplace violence within the past 12 months. The objective of this study was to quantify the frequency and characterize the types of workplace violence experienced by physicians working in EDs in Turkey.

\section{Materials and Methods}

\section{Study Design and Setting}

This study was a cross-sectional online survey of workplace violence experienced by physicians working in EDs in Turkey. The survey (Appendix 1) was modeled after a statewide survey of emergency physicians in Michigan ${ }^{2}$ who recalled experiencing violent encounters from the past 12 months. Our survey was translated into Turkish and tested among six Turkish emergency physicians and some questions were modified per their recommendations. We used an electronic survey via Google that was distributed via email. This study is compliant with the Strengthening The Reporting of Observational Studies in Epidemiology (STROBE) guidelines. Approval was obtained from the Ethics Department (IRBequivalent) at Hasan Kalyoncu University, Gaziantep, Turkey. The survey was voluntary and consent was given by way of clicking past the first page online.

\section{Selection of Participants}

A list of physicians, including residents, working in EDs was obtained from a national emergency physicians association. Email invitations to participate in the online survey were sent to 2,454 physicians beginning October 20, 2017. Because only 100 surveys could be distributed per day, emails were distributed over a 25-day period. A follow-up email to nonresponders was sent after approximately 1 month. The study period closed in January 1,2018 . To focus on physicians primarily working clinically in the ED, an a priori decision was made to exclude those working less than 20 hours per week.

\section{Methods of Measurement}

To allow for meaningful scientific comparison of results with other similar studies, we utilized the same four categories of violence (verbal threat, physical altercation, confrontation, and stalking) that have been used in multiple studies ${ }^{2,11,13}$ and added sexual harassment as a fifth type of violence (Appendix 2).

Demographic information collected of surveyed physicians included sex, medical training, number of hours worked, timing of clinical shifts, population size served in location of primary hospital of employment, type of hospital, whether the hospital has an emergency medicine residency program, and the estimated number of patients per day seen in the ED.

Surveys included characteristics of the perpetrators and physicians' reactions to the violence experienced. Perpetrators of violence were further categorized as being the patient, family member, patient's friend, and whether the perpetrator appeared to be clinically intoxicated with alcohol or drugs, or if they seemed mentally unstable. Incidents of workplace violence within the past 12 month were categorized according to frequency $(0,1-2,3-5,6-10$, $>10$ episodes).

Response to violence was assessed by inquiring about forms of personal protection used, and longstanding psychological effects of workplace violence were evaluated. We also assessed participants' immediate reaction to violence and if services designed to prevent, mitigate, and manage workplace violence are offered to staff at the hospitals our participants work in, and if survey participants are interested in such resources. Participants were also queried to whom, if anyone, they reported the violent incident(s) to, and if they personally fear being victimized at work. Information about presence and effectiveness of hospital security and police services, feedback on presence of laws and hospital rules to protect staff from violence, and whether hospitals employed any rules limiting the number of visitors and loitering were also obtained. The perception of improving or worsening safety at the workplace over the course of the participant's professional career was assessed, as were possible causes for the violent attacks.

\section{Data Collection and Processing}

In an attempt to minimize duplicate entries, surveys were individually numbered in Google and their links were deactivated upon survey completion. Responses were automatically saved into an online repository (Google). The data were exported into Excel for analysis. All data were collected electronically and anonymously.

\section{Primary Data Analysis}

The normality of distribution of continuous variables was tested by Shapiro-Wilk test. Mann-Whitney $U$ test was used for comparison of two independent groups of variables with a nonnormal distribution. Chi-square test was used to assess relation between categorical variables and Bonferroni-adjusted significance level was used to determine significance and account for multiple testing. Descriptive statistic parameters were presented as frequency, percentage (\%), and mean \pm standard deviation. Statistical analysis was performed with SPSS (Version 22.0; SPSS Inc., Chicago, 
Illinois, United States) and a $p$-value of $<0.05$ was accepted as statistically significant.

\section{Results}

Three hundred sixty-six physicians completed the survey; 4 were excluded because they worked less than 20 hours/week clinically. A total of 362 responders were included. Sixty-two percent of respondents were men and 38\% were women. Sixty-two percent were attending physicians, 27\% were emergency medicine residents, and $12 \%$ were general practitioners working full-time in the ED ( - Table 1). Our study included residents working in EDs because they often work without an attending physician immediately available. Sixty-nine percent of respondents work primarily in an urban (> 500,000 population) environment, $28 \%$ work in suburban areas ( $<500,000$ population), and $3 \%$ in rural locations. Thirty-seven percent work in state hospitals, 31\% at university hospitals, $28 \%$ at training research hospitals, and 3\% work in private hospitals. The average number of ED patients per day was 334.

Over 99\% ( $n=356)$ of physicians reported verbal abuse and $54 \%(n=196)$ reported experiencing physical violence while working in the ED ( $\sim$ Fig. 1). Forty-three percent ( $n=157)$ experienced confrontation, 24.9\% $(n=90)$ reported stalking, and $6.1 \%(n=22)$ reported sexual harassment (-Table 2).

Family members of patients, not the patients themselves, were the most common perpetrators of every form of workplace violence (verbal, physical, confrontation, stalking, and sexual harassment) (- Table 3 ). This coincides with our finding that hospitals limiting loitering and the number of visitors were associated with a $14 \%$ absolute reduction in the number of physicians reporting physical threats and $11 \%$ reduction in number of physicians reporting confrontations in comparison to the baseline prevalence of violence in the entire study (- Table 4).

Table 1 Demographic information of participants

\begin{tabular}{|c|c|}
\hline & $n(\%)$ \\
\hline \multicolumn{2}{|l|}{ Sex } \\
\hline Female & $137(37.8)$ \\
\hline Male & $225(62.2)$ \\
\hline \multicolumn{2}{|l|}{ Employment } \\
\hline General practitioner & $42(11.6)$ \\
\hline Nonacademic emergency physician & $198(54.7)$ \\
\hline Emergency resident & $96(26.5)$ \\
\hline $\begin{array}{l}\text { Academic emergency attending } \\
\text { physician }\end{array}$ & $26(7.2)$ \\
\hline \multicolumn{2}{|l|}{ Location of primary hospital employment } \\
\hline Urban (population > 500,000) & $247(68.2)$ \\
\hline Urban (population $<500,000$ ) & $102(28.2)$ \\
\hline Suburban & $7(1.9)$ \\
\hline Rural & $6(1.7)$ \\
\hline
\end{tabular}

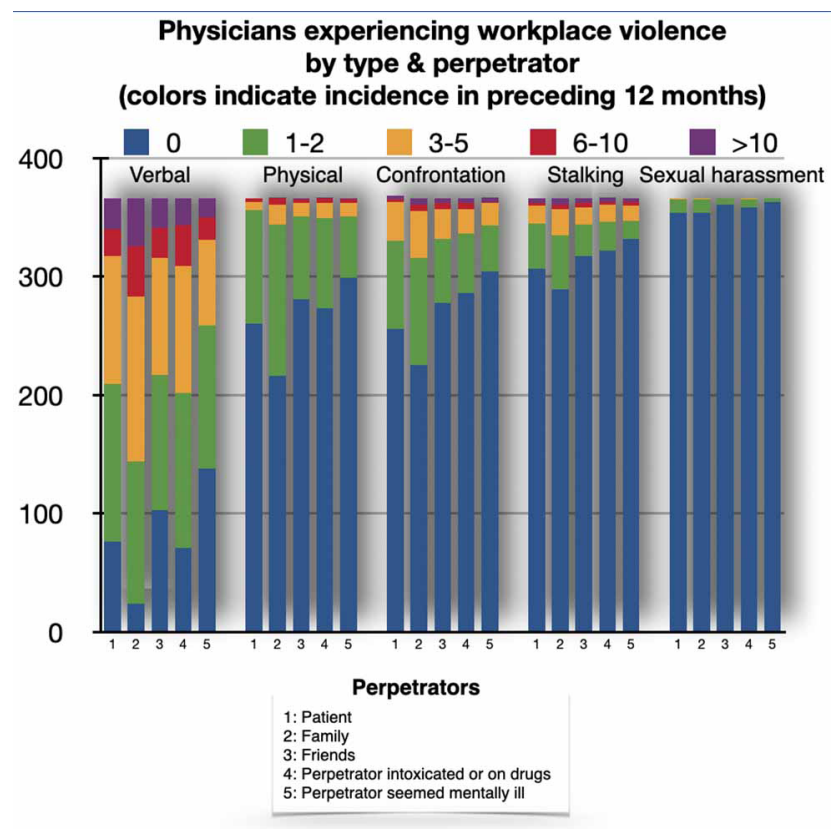

Fig. 1 Physicians experiencing workplace violence (by type and perpetrator, in preceding 12 months).

Only $23 \%$ of respondents indicated that their hospital offered information about preventing and managing workplace violence even though $86 \%$ noted interest in outside resources including legal and psychological support, conflict de-escalation techniques, and self-defense classes. Thirty percent of respondents constantly fear and 36\% frequently fear becoming a victim of workplace violence while only $1 \%$ never had fear. These numbers are surprising given that $89 \%$ indicated they had security staff that round in the ED and the rest of the hospital and $46 \%$ had police officers in their hospital. Less than $2 \%$ had no security staff. Eighty-nine percent of respondents felt that their hospital does not employ a sufficient number of security staff, and $94 \%$ felt that security guards or police do not provide adequate protection from violent encounters ( - Table 5 ). Ninety-two percent of respondents indicated that their hospital does not employ rules preventing loitering and $87 \%$ stated their hospital does not limit the number of visitors. Ninety percent indicated that current laws do not adequately protect them. Eighty-two percent indicated that workplace violence has affected their ability to provide patient care.

Of all types of violence reported (verbal, physical, confrontation, stalking, and sexual harassment), only verbal abuse and stalking demonstrated a statistically significant difference between men and women (30.2\% vs. $16.1 \%$ of men and women, respectively, reported having been stalked, $p=$ 0.004 ) (-Table 2). Number of years of experience was not correlated with likelihood of experiencing physical violence, confrontation, stalking, or sexual harassment.

When asked about the suspected reasons that led to the violence experienced, physicians cited inappropriate medical demands from patients such as unjustified medication prescriptions, unnecessary work notes, unnecessary laboratory work to be performed (93.9\%), alcohol and drug abuse 
114 Workplace Violence in Emergency Departments in Turkey Sabak et al.

Table 2 Physicians experiencing violence, by gender and type of violence

\begin{tabular}{|c|c|c|c|c|}
\hline & & \multicolumn{2}{|c|}{ Physicians } & \multirow[t]{3}{*}{$p$-value } \\
\hline & & Men & Women & \\
\hline & & $n(\%)$ & $n(\%)$ & \\
\hline \multirow[t]{2}{*}{ Verbal threat } & Yes & $219(97.3)$ & $137(100)$ & \multirow[t]{2}{*}{0.016} \\
\hline & No & $6(2.7)$ & $0(0 \%)$ & \\
\hline \multirow[t]{2}{*}{ Physical violence } & Yes & $128(56.9)$ & $68(49.6)$ & \multirow[t]{2}{*}{0.173} \\
\hline & No & $97(43.1)$ & $69(50.4)$ & \\
\hline \multirow[t]{2}{*}{ Confrontation } & Yes & $105(46.7)$ & $50(36.5)$ & \multirow[t]{2}{*}{0.099} \\
\hline & No & $120(53.3)$ & $87(63.5)$ & \\
\hline \multirow[t]{2}{*}{ Stalking } & Yes & $68(30.2)$ & $22(16.1)$ & \multirow[t]{2}{*}{0.004} \\
\hline & No & $157(69.8)$ & $115(83.9)$ & \\
\hline \multirow[t]{2}{*}{ Sexual harassment } & Yes & $15(6.7)$ & $7(5.1)$ & \multirow[t]{2}{*}{0.549} \\
\hline & No & $210(93.3)$ & $130(94.9)$ & \\
\hline
\end{tabular}

Table 3 Rates of workplace violence, by type of violence and perpetrator

\begin{tabular}{|l|l|l|l|l|l|l|l|}
\hline Total $n=362$ & \multicolumn{2}{|l}{ Number of physicians experiencing violence (\% of total $n)$} \\
\hline & $\begin{array}{l}\text { Physicians } \\
\text { attacked (by } \\
\text { any form of } \\
\text { violence) }\end{array}$ & Verbal threat & $\begin{array}{l}\text { Physical } \\
\text { assault }\end{array}$ & $\begin{array}{l}\text { Confrontation } \\
\text { after patient } \\
\text { care }\end{array}$ & Stalking & $\begin{array}{l}\text { Sexual } \\
\text { harassment }\end{array}$ \\
\hline Perpetrators & $299(82.6 \%)$ & $286(79 \%)$ & $104(28.7 \%)$ & $109(30.1 \%)$ & $58(16.0 \%)$ & $12(3.3 \%)$ \\
\hline Patient & $344(95 \%)$ & $338(93.4 \%)$ & $150(41.4 \%)$ & $140(38.7 \%)$ & $76(21 \%)$ & $12(3.3 \%)$ \\
\hline Family member & $269(74.3 \%)$ & $261(72.1 \%)$ & $84(23.2 \%)$ & $87(24.0 \%)$ & $48(13.3 \%)$ & $5(1.4 \%)$ \\
\hline Friend of patient & $298(82.3 \%)$ & $293(80.9 \%)$ & $93(25.7 \%)$ & $79(21.8 \%)$ & $43(11.9 \%)$ & $8(2.2 \%)$ \\
\hline Intoxicated & $240(66.3 \%)$ & $227(62.7 \%)$ & $67(18.5 \%)$ & $62(17.1 \%)$ & $34(9.4 \%)$ & $3(0.8 \%)$ \\
\hline Mentally ill &
\end{tabular}

Table 4 Impact of preventing loitering on rate and types of violence

\begin{tabular}{|c|c|c|c|c|}
\hline & & \multicolumn{3}{|c|}{$\begin{array}{l}\text { Does your hospital employ rules that prevent patients and visitors from } \\
\text { loitering in the emergency department? }\end{array}$} \\
\hline & & Yes & No & \multirow[t]{2}{*}{$p$-value } \\
\hline & & \multicolumn{2}{|l|}{$n(\%)$} & \\
\hline \multirow[t]{2}{*}{ Verbal threat } & Yes & $29(100)$ & $322(98.2)$ & \multirow[t]{2}{*}{0.311} \\
\hline & No & $0(0)$ & $6(1.8)$ & \\
\hline \multirow[t]{2}{*}{ Physical threat } & Yes & $9(31.0)$ & $182(55.5)$ & \multirow[t]{2}{*}{0.011} \\
\hline & No & $20(69.0)$ & $146(44.5)$ & \\
\hline \multirow[t]{2}{*}{ Confrontation } & Yes & $19(65.5)$ & $133(40.5)$ & \multirow[t]{2}{*}{0.009} \\
\hline & No & $10(34.5)$ & $195(59.5)$ & \\
\hline \multirow[t]{2}{*}{ Stalking } & Yes & $6(20.7)$ & $82(25.0)$ & \multirow[t]{2}{*}{0.606} \\
\hline & No & $23(79.3)$ & $246(75.0)$ & \\
\hline \multirow[t]{2}{*}{ Sexual harassment } & Yes & $1(3.4)$ & $21(6.4)$ & \multirow[t]{2}{*}{0.494} \\
\hline & No & $28(96.6)$ & 307 (93.6) & \\
\hline
\end{tabular}

(71.9\%), critical condition or death of a patient (58.1\%), long time spent in $\operatorname{ED}(51.8 \%)$, long time spent in the waiting room (41.3\%), and mental health disorders (38.8\%). Two common themes that emerged from free-text responses included excessive amounts of visitors and lack of legal protections for physicians.

While we suspected that physicians who were excluded a priori because they work less than 20 hours per week 
Table 5 Impact of police and security guards on rate and types of violence

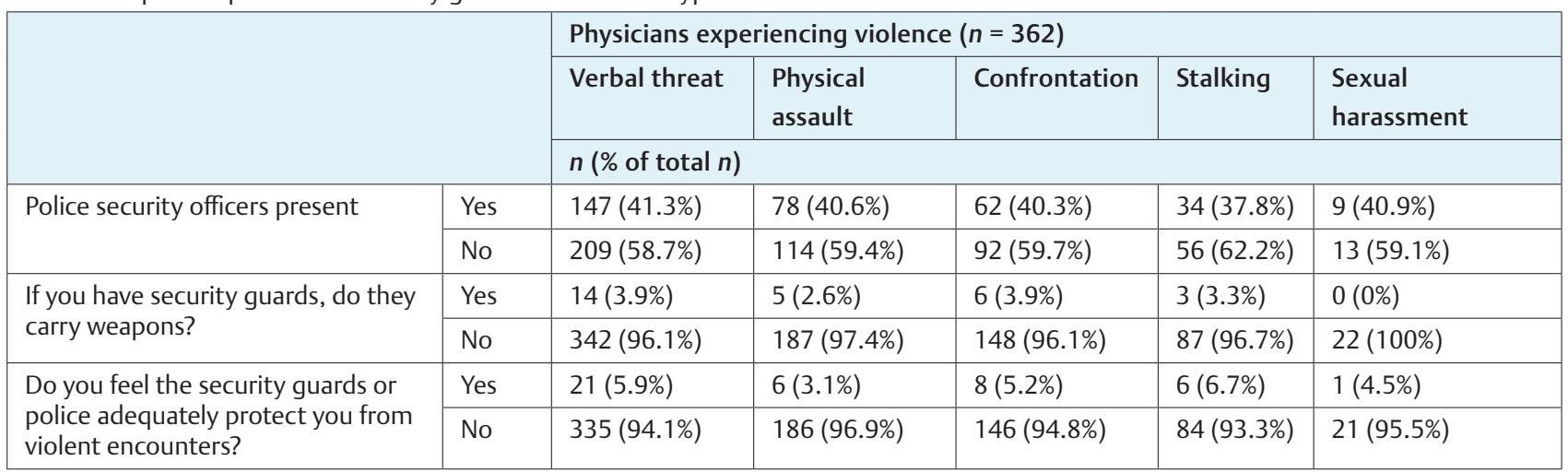

clinically may not experience workplace violence as often, all 4 excluded physicians cited some form of violence experienced in the preceding 12 months, similar to the included cohort.

\section{Discussion}

Workplace violence is a serious public health problem and occupational hazard that is usually underreported ${ }^{14}$ and continues to worsen. EDs have the highest rates of workplace violence of any department in hospitals, ${ }^{15}$ likely due to high acuity of pathology, perceived long wait times, increased levels of stress among patients and family members, ED overcrowding, poor staffing levels, unrealistic clinical expectations, availability of weapons including a lack of screening by hospitals possibly concerned about projecting an unsafe image to potential patrons, the general perception that violence is tolerated with reporting incidents having no effect, among other factors. ${ }^{16}$

While some studies have reported on workplace violence in EDs in Turkey, ${ }^{8,10-12,17-20}$ only one study has attempted to evaluate the rate of workplace violence among physicians working in EDs in Turkey on a national level. ${ }^{9}$

Rates of workplace violence experienced by physicians working in EDs in Turkey are similar to results from previous studies of physicians ${ }^{9}$ and health care providers ${ }^{20}$ in Turkey and those in Ankara, Turkey. ${ }^{11}$ Our results (-Table 2) are also comparable to those from prior studies performed in Michigan by Kowalenko et $\mathrm{al}^{2}$ and Omar et al, ${ }^{13}$ and across residency programs in the United States. ${ }^{7}$ We found that $99.4 \%$ had been subjected to at least one form of violence, which is very similar to findings by Bayram et al (99.7\%). ${ }^{9}$ Verbal abuse was reported by over $99 \%$ of physicians in Turkey versus $75 \%$ of attending emergency physicians in Michigan ${ }^{2}$ and $75 \%$ of residents and attending physicians across the United States. ${ }^{7}$ Physical abuse was reported by $54 \%$ of physicians in Turkey versus $38.1 \%$ in Michigan ${ }^{13}$ and $47 \%$ across the U.S. in a national survey conducted by the American College of Emergency Physicians. ${ }^{21}$ Previous studies of workplace violence report rates of verbal abuse of $80 \%$ in Ankara ${ }^{11}$ and $88.6 \%$ in Denizli, ${ }^{20}$ while rates of physical violence range from $41 \%$ in Ankara ${ }^{11}$ to $49.4 \%$ in Denizli. ${ }^{20}$ These results suggest that acts of workplace violence occur more frequently in
Turkey when compared with the United States, although the differences are subtle.

While some studies report that the most common perpetrators of violence are patients, ${ }^{21-23}$ often under the influence of alcohol or drugs, or suffering from mental health conditions, ${ }^{20}$ we found that relatives of patients were the main perpetrators of every form of violence measured. This is consistent with results from India as reported by Sachdeva et al, ${ }^{24}$ Iran as reported by Shoghi et al, ${ }^{6}$ and Turkey as reported by Talas et al, ${ }^{11}$ Acik et $a l,{ }^{17}$ Aydin et $a{ }^{18}$ Ayranci, ${ }^{19}$ Boz et al, $^{20}$ and Erkol et al. ${ }^{12}$ This difference suggests that while the problem of workplace violence is similar in many countries across the globe, the specific causes differ and proposed solutions should be tailored accordingly.

The Occupational Safety and Health Administration lists unrestricted public access as one of the many contributors to workplace violence. ${ }^{16}$ We found that hospitals that limited the number of visitors and prevented loitering were associated with a $14 \%$ absolute reduction in physicians reporting physical threats and an $11 \%$ absolute reduction in physicians reporting experiencing confrontations. Given that $87 \%$ of physicians indicated that their EDs do not limit the number of visitors and $92 \%$ do not prevent loitering, we believe restricting access to a select number of visitors per patient has the potential to significantly decrease the rates of workplace violence across the vast majority of EDs in Turkey.

Only $23 \%$ of respondents indicated that their hospital offered information about preventing and managing workplace violence even though $86 \%$ noted interest in outside resources including legal and psychological support, conflict de-escalation techniques, and self-defense classes. This may explain why Talas et $\mathrm{al}^{11}$ found that the main reaction to violence was that victims of workplace violence "did nothing and kept silent." Arming physicians with these tools may prevent the development of a helpless mentality many may experience before, during, or after a violent attack. The high rates of physicians feeling unsafe at work are surprising given that $89 \%$ indicated they had security staff that round in the ED and the rest of the hospital. Forty-six percent had police officers in their hospital. Less than $2 \%$ had no security staff. Eighty-nine percent of respondents felt that their hospital does not employ a sufficient number of security staff, and $94 \%$ felt that security guards or police do not adequately 
protect them from violent encounters. This explains why the rate of every form of violence was unchanged whether there was police security officers. However, the minority of physicians who had security guards that carried weapons reported lower rates of every type of violence ( - Table 5 ). This all suggests that the physical presence of security personnel alone may not suffice and that greater authority for them to disperse or detain dangerous or abusive individuals may be of benefit. Limits to the authority and willingness to enforce laws and rules, or to use force by security personnel is likely influenced by cultural norms and expectations as well as the lack of any specific legal protection afforded to health care workers. Anecdotally, many security officers have mentioned lack of legal protection from perpetrators of violence as the reason for not protecting health care workers, because many are privately employed security guards and not government employees like police officers. Ninety percent of physicians indicated that current laws do not adequately protect them. This has been exemplified repeatedly in perpetrators of violence against physicians often suffering little legal ramifications, often being released from jail before the victimized physicians were discharged from the hospitals treating their injuries. ${ }^{25}$ Between the presentation of this abstract and the publication of this article, Turkey passed a federal law ${ }^{26}$ punishing perpetrators of violence against health care providers with 1.5 times the normal sentence. The impact of this law has yet to be seen.

Eighty-two percent indicated that workplace violence has affected their ability to provide patient care. Erdur et $\mathrm{al}^{27}$ found that physicians experiencing workplace violence in Turkey exhibited higher levels of burnout. The cost of recruiting, hiring, and training nurses can be expensive. While workplace violence has traditionally been considered a problem of an individual victim, the reality is that hospitals and the entire health care system are adversely impacted by these transgressions.

We believe overcrowding and understaffing of EDs in Turkey is an important contributor to the high levels of workplace violence. In 2015, there were over 110 million ED visits in Turkey ${ }^{28}$ which was approximately 1.43 visits/person, a rate more than three times higher than 0.43 visits/person in the United States. ${ }^{29}$ Systemic overreliance on EDs for care that costs nothing to patients leading to overcrowding combined with high patient expectations and systemic understaffing of physicians likely contributes to the higher rates of workplace violence. In many hospitals, it is not uncommon for physicians to be required to see 10 patients per hour. Patient and family expectations for cures and perceived lack of repercussions for violence also are likely to be important factors contributing to the high rates of workplace violence.

\section{Limitations}

Even though physical altercations and stalking usually invoke strong visceral reactions and memories, the retrospective nature of this study may introduce recall bias. Prospective studies would be beneficial. The response rate of $14.9 \%$, while similar to the $11 \%$ response rate in the American College of Emergency Physicians' survey on workplace violence, ${ }^{21}$ was low which may impair our ability to generalize results. The large number of questions, while providing good insight into this problem, likely contributed to a lower response rate. While physicians completing surveys are probably more likely to have experienced violence, even if all the nonresponders experienced no violence, having 14.4 and $9.7 \%$ of physicians experience verbal abuse and physical assaults, respectively, would still be considered unacceptable in any work environment. Suspicion of alcohol or drug use in the perpetrators of violence was likely the subjective opinion of the physician. Less than $3 \%$ of responders worked in rural areas which may introduce selection bias as busier EDs with sicker patients may be overrepresented.

\section{Conclusion}

In conclusion, workplace violence is a real danger experienced by physicians working in EDs in Turkey, similar to those in the United States demonstrating this problem transcends borders. Limiting the number of visitors and preventing loitering was associated with a lower incidence of violent attacks. Our results suggest that the more frequent perpetrators of violence (patients' family and friends in Turkey as opposed to an intoxicated or mentally unstable patient in the U.S.) vary. The difference in the root causes highlights the need for nuanced solutions. Further studies should assess root causes of violent behaviors of patients and their visitors, perceived or actual hindrances limiting security personnel's ability to protect physicians, as well as possible (administrative, social, and legal) mechanisms to minimize such violence.

\section{References}

1 Occupational Safety and Health Administration; Worker Safety in Hospitals: Caring for our Caregivers. Available at: https://www.osha.gov/dsg/hospitals/workplace_violence. html. Accessed June 24, 2020

2 Kowalenko T, Walters BL, Khare RK, Compton S. Michigan College of Emergency Physicians Workplace Violence Task Force Workplace violence: a survey of emergency physicians in the state of Michigan Ann Emerg Med 2005;46(2):142-147

3 McGovern P Kochevar L Lohman $\mathrm{W}$ et al The cost of work-related physical assaults in Minnesota Health Serv Res 2000;35(3):663-686

4 Lavoie FW, Carter GL, Danzl DF, Berg RL. Emergency department violence in United States teaching hospitals. Ann Emerg Med 1988;17(11):1227-1233

5 Noorana Zahra A, Feng JY, Workplace violence against nurses in Indonesian emergency departments Enferm Clin 2018 28; Suppl:(1):184-190

6 Shoghi M, Sanjari M, Shirazi F, Heidari S, Salemi S, Mirzabeigi G. Workplace violence and abuse against nurses in hospitals in Iran Asian Nurs Res 2008;2(3):184-193

7 Behnam M, Tillotson RD, Davis SM, Hobbs GR. Violence in the emergency department: a national survey of emergency medicine residents and attending physicians. J Emerg Med 2011;40(5):565-579 
8 Çıkrıklar HÍ, Yürümez Y, Güngör B, Aşkın R, Yücel M, Baydemir C. Violence against emergency department employees and the attitude of employees towards violence Hong Kong Med J 2016;22(5):464-471

9 Bayram B, Çetin M, Çolak Oray N. Can İÖ Workplace violence against physicians in Turkey's emergency departments: a cross-sectional survey BMJ Open 2017;7(6):e013568

10 Baydin A, Erenler AK. Workplace violence in emergency department and its effects on emergency staff. Int J Emerg Ment. Health 2014;16(2):288-290

11 Talas MS, Kocaöz S, Akgüç S. A. survey of violence against staff working in the emergency department in Ankara, Turkey Asian Nurs Res 2011;5(4):197-203

12 Erkol H, Gökdoğan MR, Erkol Z, Boz B. Aggression and violence towards health care providers--a problem in Turkey? J Forensic Leg Med 2007:14(7):423-428

13 Omar H, Yue R, Amen A, Kowalenko T, Walters BL. Reassessment of violence toward emergency medicine physicians in Michigan Am J Emerg Med;2019

14 Richardson SK, Grainger PC, Ardagh MW, Morrison R. Violence and aggression in the emergency department is under-reported and under-appreciated. N Z Med J 2018;131(1476):50-58

15 Stultz MS. Crime in hospitals 1995: the latest International Association for Healthcare Security and Safety Survey J Healthc Prot Manage 1996-1997;13(1):45

16 Workplace Violence in Healthcare. Understanding the Challenge. Available at: https://www.osha.gov/Publications/ OSHA3826.pdf. Accessed June 24, 2020

17 Acik Y, Deveci SE, Gunes G, et al. Experience of workplace violence during medical speciality training in Turkey. Occup Med (Lond 2008;58(5):361-366

18 Aydin B, Kartal M, Midik O, Buyukakkus A. Violence against general practitioners in Turkey J Interpers Violence 2009; 24(12):1980-1995

19 Ayranci U. Violence toward health care workers in emergency departments in west Turkey.J Emerg Med 2005;28(3):361-365
20 Boz B Acar K Ergin A et al Violence toward health care workers in emergency departments in Denizli, Turkey Adv Ther 2006; 23(2):364-369

21 ACEP Emergency Department Violence Poll Research Results. Available at: https://www.emergencyphysicians.org/globalassets/files/pdfs/2018acep-emergency-department-violence-pollresults-2.pdf. Accessed June 23, 2020

22 Sentinel Event Alert. Available at: https://www.jointcommission.org/-/media/documents/office-quality-and-patient-safety/sea_59_workplace_violence_4_13_18_final. pdf?db=web\&hash=9E659237DBAF28F07982817322B99FFB. Accessed June 23, 2020

23 Fact Sheet | Workplace Violence in Healthcare, 2018 | April 2020. (n.d.). Available at: https://www.bls.gov/iif/oshwc/ cfoi/workplace-violence-healthcare-2018.htm. Accessed June 16, 2020

24 Sachdeva S, Jamshed N, Aggarwal P, Kashyap SR. Perception of workplace violence in the emergency department. J Emerg Trauma Shock 2019;12(3):179-184

25 Sağlık Personeli Haber Kaynağı. 2 Doktoru Darp Eden Hasta Yakını Serbest Bırakıldı; May 27, 2020. Available at: www. saglikpersonelihaber.net/gundem/2-doktoru-darp-eden-hasta-yakini-serbest-birakildi-h7649.html. Accessed June 23, 2020

26 Republic of Turkey. Official Newspaper. Available at: https:// www.resmigazete.gov.tr/eskiler/2020/04/20200417-1.htm. Accessed June 26, 2020

27 Erdur B Ergin A Yüksel A Türkçüer İ Ayrık C Boz B Assessment of the relation of violence and burnout among physicians working in the emergency departments in Turkey Ulus Travma Acil Cerrahi Derg 2015;21(3):175-181

28 General Health Statistics. Summary Information. Available at: https://rapor.saglik.gov.tr/istatistik/rapor/. Accessed June 24, 2020

29 Emergency Department Visits. Available at: https://www. cdc.gov/nchs/fastats/emergency-department.htm. Accessed June 24, 2020 